\title{
Genetic Relatedness of Diplostomum Species (Digenea: Diplostomidae) Infesting Nile Tilapia (Oreochromis Niloticus L.) in Western Kenya
}

\author{
Violet M. Ndeda*, Dickson O. Owiti, Ben O. Aketch, David M. Onyango \\ Department of Zoology, Maseno University, Kisumu City, Kenya \\ Email: *vmmbone@yahoo.com
}

Received May 24, 2013; revised June 26, 2013; accepted July 3, 2013

Copyright (C) 2013 Violet M. Ndeda et al. This is an open access article distributed under the Creative Commons Attribution License, which permits unrestricted use, distribution, and reproduction in any medium, provided the original work is properly cited. In accordance of the Creative Commons Attribution License all Copyrights (C) 2013 are reserved for SCIRP and the owner of the intellectual property Violet M. Ndeda et al. All Copyright (C) 2013 are guarded by law and by SCIRP as a guardian.

\begin{abstract}
Diplostomum species metacercariae are trematode parasites that pose serious economic threats to aquaculture practice globally. Identification of Diplostomum at metacercariae stage has remained equivocal, hence lack of elucidation of the actual role of these species in fish population. 21 Diplostomoid metacercariae obtained from eyes of Nile tilapia were characterized using 18S and ITS rDNA (ITS1-5.8S-ITS2) genes. Phylogenetic analyses of ITS rDNA gene dataset in the metacercariae revealed close relationship to Diplostomum mashonense and D. baeri. Molecular identification using $18 \mathrm{~S}$ rDNA sequences revealed close relationship to $D$. compactum, $D$. phoxini and $D$. spathaceum. Overall, genetic analyses in this study depicted a significant unrecognized genetic diversity among Diplostomum species. Successful differentiation of Diplostomum genera in this study using ribosomal markers suggested that 18S and ITS rDNA genes are effective genetic markers for inter-species phylogenetic analysis and should be employed in future for identification of diplostomoidea.
\end{abstract}

Keywords: Diplostomum; 18S rDNA; Internal Transcribed Spacer Region

\section{Introduction}

Diplostomum metacercariae are trematode parasites with complex three host lifecycle that are considered major pathogens of fish. They mature in the small intestine of piscivorous birds and are passed on to snails as first intermediate host and fish as second intermediate host during their life cycle [1]. Once attached to the fish, Diplostomum metacercariae moves to the lens, retina and aqueous humour of fish eyes as well as the brain, spinal cord and nasal spaces thereby resulting into substantial losses of wild and farmed fish [1,2].

Diplostomum parasites have been encountered in fish farms in the northern hemisphere (Europe and North America) and as such received wide theoretical and empirical attention due to their pathogenic consequences to fingerlings [3-6]. The eye fluke infection has been associated with decreased growth of fish in rearing conditions $[7,8]$ and increased mortality in fish as a result of reduced

${ }^{*}$ Corresponding author. vision caused by cataracts which impairs the fish's feeding efficiency [9] and makes the fish more vulnerable to avian predation [10]. Taxonomic studies on the diplostomid digeneans from the African continent are scarce and limited to few Diplostomum species descriptions published between 1930s-1960s, and virtually little is known of their natural history [e.g., 11,12]. This is related to low sampling efforts in tropical countries due to lack of expertise in the field of fish parasitology. In addition, identification of these parasites is problematic due to 1 ) the presence of morphologically similar species; 2) the phenotypic plasticity of the adults and metacercariae; 3) the simple larval morphology; and 4) the difficulties in linking life-cycle stages [13].

These problems represent a major impediment for the assessment of the distribution and the actual role of diplostomids in fish populations. Furthermore, most of the published African diplostomid studies have focused on the catfish Clarias gariepinus [14-17]. Recently, reports have indicated presence of Diplostomiasis infection 
among Oreochromis niloticus in Kenya [18,19] and from another African freshwater fish host, Synodontis nigrita [17] in Nigeria. This is an indication that Diplostomum parasites affect a number of fish species and therefore more research should be undertaken to elucidate the diversity of these parasites in other fish populations. As such, basing taxonomic identification of African Diplostomum species to a few ancient descriptions is misleading. In addition, relying on results from one fish species (Clarias gariepinus) makes it unreliable to extrapolate results to other fish species because of differences in feeding and resting behaviours among fish species. Inappropriate naming of Diplostomum species in tropical countries has led to misidentification of the species and thus inaccurate estimates of species diversity. For example, a study by [16] assigned the name $D$. mashonense to a parasite species recovered from the brain of clarid fish in Tanzania, however, a recent study on the same by [17], elicited a controversy in the naming of the parasites thereby reallocating $D$. mashonense to Tylodelphys mashonense using ITS1-5.8S-ITS2 molecular markers. This controversy depicts a complicated taxonomic situation in Africa coupled with poor taxonomic resources and expertise. Therefore, misidentification of species is a fact that cannot be neglected because, concurrent infections with the eye-infecting diplostomids appear to be frequent and widespread geographically being reported in Tanzania, South Africa and Kenya [16,19,20].

This fact, coupled with the morphological similarity of the metacercariae makes the practical species diagnosis based on morphology very difficult. Use of rapid and accurate molecular identifications using standardized tools and barcoding approaches appear most suited [21] for unravelling diplostomid taxonomic diversity in different regions worldwide.

To date, a total of eight named species of Diplostomum using ITS rDNA sequences are now available. These include: complete sequences of the ITS1-5.8SITS2 gene cluster for Diplostomum huronense (La Rue, 1927), Diplostomum indistinctum (Guberlet, 1923) and Diplostomum baeri (Dubois, 1937) from fish and/or gulls collected in Canada [22-24] and partial ITS1 sequences for Diplostomum baeri, Diplostomum mergi (Dubois, 1932), Diplostomum paracaudum (Iles, 1959), Diplostomum parviventosum (Dubois, 1932), Diplostomum pseudospathaceum (Niewiadomska, 1984) and Diplostomum spathaceum (Rudolphi, 1819) from larval stages collected in Poland [25]. Furthermore, ITS1-5.8S-ITS2 sequences for nine additional presumed species (unidentified isolates labelled as Diplostomum spp. 1-9) have been generated recently from fish metacercariae in Canada $[23,24,26]$. These studies only shed light on previous studies conducted in the St. Lawrence River in Canada which is geographically limited to the northern he- misphere (Europe and North America). Therefore more research should be prioritized on Diplostomum parasites affecting fish in order to update the taxonomic database in Africa. The principal goal of this study was to establish the genetic relatedness of Diplostomum spp. parasitizing populations of Oreochromis niloticus L. within Kisumu municipality, in western Kenya using ribosomal molecular markers.

\section{Materials and Methods}

The study was conducted in three locations within Kisumu municipality (Figure 1) bordering Lake Victoria in western Kenya, after every 3 weeks from December, 2011 to February, 2012. Kisumu region was preferred for the study because of the Economic Stimulus Program (ESP) initiated by the government in 2009 that targeted fish farmers in the region and led to the construction of over 300 fish ponds in the municipality. In addition, Kisumu region experiences four distinct seasons, i.e. two rainy seasons and two dry seasons. The rainy seasons are further sub-divided into the long rainy season and the short rainy season [27]. Likewise, the dry season is also subdivided into a long dry season, and a short dry season. The long rainy season usually begins in March through to May. This is normally followed by a long dry spell, which starts in June and ends in August. The short rainy season starts in October and lasts for two months until November, followed by the long dry spell which starts in December through to February [28]. Period of sampling for this study (December 2011-February 2012) was preferred based on previous literature by [19] in Kenya that reported diplostomid transmission patterns to be higher during dry seasons compared to wet seasons. Maximum temperatures in Kisumu occur in the long dry spell with an annual maximum temperature range of about $27^{\circ} \mathrm{C}$ to about $32^{\circ} \mathrm{C}$ [29]. Minimum temperature ranges from $14^{\circ} \mathrm{C}$ to $18^{\circ} \mathrm{C}$, with the peak minimum temperature recorded in August through September [29]. At least three farms were selected per location based on their proximity to one hatchery centre in the municipality which serves as source of the much required quality fingerlings for supply to prospective farmers. These locations border each other hence ease of accessibility.

\subsection{Fish Sampling Procedure and Transportation}

Sample size used in this study was estimated according to the formula by [30]. Sampling was done in three main settlement areas of Kisumu after every three weeks for a period of three months (December 2011-February 2012). Sixty four (64) Nile tilapia fish were randomly sampled per pond, for every three ponds per farm using a seine net of $1.5 \mathrm{~m}$ diameter and $6 \mathrm{~mm}$ mesh. Therefore a total 


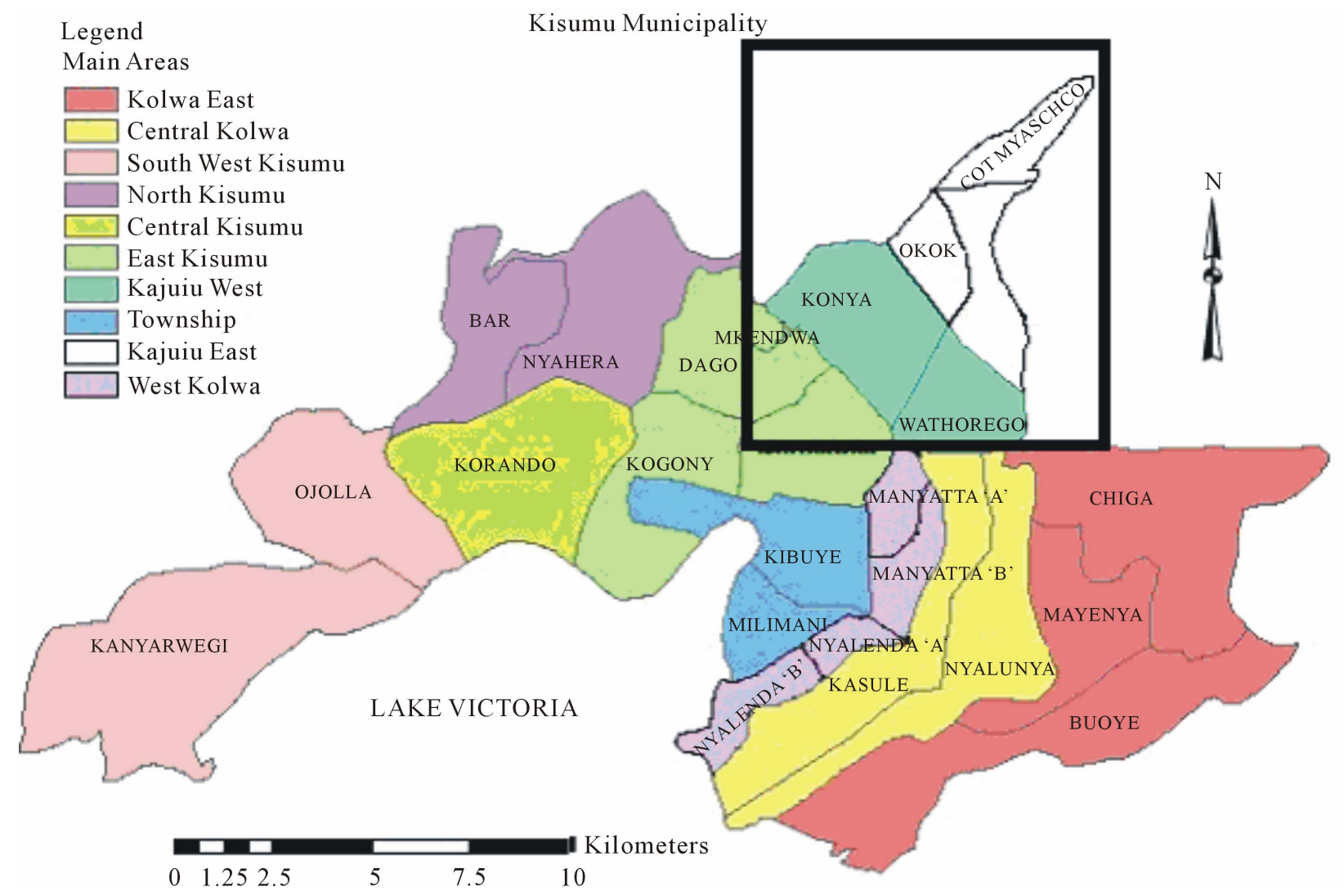

Figure 1. Map showing Kisumu Municipality and the study area (marked in box).

of 27 fish ponds were sampled in Kisumu municipality. Sampled fish were then transported in an iced cool box at $8^{\circ} \mathrm{C}$ to the department of Zoology laboratory, Maseno University, for further analysis.

\subsection{Laboratory Procedures}

\subsubsection{Examination of Fish Specimens for Diplostomum Parasites}

Fish eyes were dissected and then examined for metacercariae with a stereoscopic microscope using procedures described by [31]. The metacercariae extracted from each eye were counted as separate lots, and placed in a petri dish containing saline solution before storing in $95 \%$ ethanol. Isolated metacercariae were stored in microcentrifuge tubes at $4^{\circ} \mathrm{C}$ and labeled according to their collection sites.

\subsubsection{Genetic Characterization of Diplostomum Species}

DNA was extracted from individual diplostomoids following the method of [32]. DNA amplification of the $18 \mathrm{~S}$ rDNA sequence was performed according to protocol described by [33] using MJ Gradient thermocycler (Gene amp. PCR system 9700, Applied Biosystems USA).

Primer sequences of:

18S9F [5'TGATCCTGCCAGTAGCATATGCTTG-3'];
18S300R [5'TCAGGCTCCCTCTCCGG-3' (400 nt)]; 18S637R [5'TACGCTATTGGAGCTGGAGTTACCG3' (600 nt)] were used [33]. Amplification of the portion of the rDNA that included the complete ITS1-5.8S-ITS2 region was done via the polymerase chain reaction (PCR) in MJ Gradient thermocycler (Gene amp. PCR system 9700, Applied Biosystems USA) according to [22] protocol.

Primer sequences of:

D1 [5'-AGGAATTCCTGGTAAGTGCAAG-3'];

D2 [5'-CGTTACTGAGGGAATCCTGGT-3'] were employed [33]. The products were run through electrophoresis using a $1 \%$ agarose gel containing ethidium bromide $(0.5 \mu \mathrm{g} / \mathrm{mL})$ alongside $0.5 \mu \mathrm{g} / \mu \mathrm{l}$; Fermentas: GeneRuler $^{\mathrm{TM}} 1 \mathrm{kbp}$ DNA Ladder (for ITS) and $100 \mathrm{bp}$ (for $18 \mathrm{~S}$ ) and visualized under Ultra Violet light.

PCR products were then purified using the Gene-Jet PCR purification kit (Fermentas, No. K 0701) following the manufacturer's protocol.

\subsection{DNA Sequencing}

Sequencing was performed at the Inqaba laboratories in South Africa. ITS1-5.8S-ITS2 region was sequenced using primers BD1 ( $5^{\prime}$-GTC GTA ACA AGG TTT CCG TA-3') and BD2 (5'-TAT GCT TAA ATT CAG CGG 
GT-3') of [34] which were used as the forward and reverse primers, respectively. Sequencing for $18 \mathrm{~S}$ rDNA gene was performed using the forward PCR primer only.

\subsection{Data Analysis}

\subsubsection{Diplostomum Species Identification and Delineation}

Contiguous sequences of the small subunit region and internal transcribed spacer regions of ribosomal DNA from 21 specimens were created from forward and reverse chromatograms and edited using DNABaser version 2.7. Multiple alignments of the contigs was conducted using Muscle 3.8.31 multiple alignment software. The nucleotide sequence data of ITS rDNA and 18S rDNA sequences were then submitted to Basic Local Alignment Search Tool (BLAST,

www.ncbi.nlm.nih.gov/blast) for similarity searches in Gen Bank. MEGA version 4.0.2 [35] was used to cluster potential species using the Neighbour-Joining phenograms. The reliability of internal branches in the Neighbour-Joining trees was assessed using bootstrap analysis with 1000 replicates. The resulting networks were rooted with the out-group taxa.

\subsubsection{Neighbour-Joining Analyses of ITS rDNA and 18S rDNA Sequences from Diplostomum Specimens Collected from Fish in Kisumu Municipality}

Phylogenetic analyses were conducted based on the alignment of partial and complete sequences of ITS rDNA and 18S rDNA using the NJ method. The resultant tree as shown in Figures $\mathbf{2}$ and $\mathbf{3}$ presented bootstrap consensus values of $>50 \%$ for almost all branches confirming that the samples were indeed members of the Diplostomum genus and were closely related to Diplostomum phoxini, Diplostomum compactum, Diplostomum spathaceum, Diplostomum mashonense and Diplostomum baeri.

The NJ analyses for 18S rDNA sequences alone revealed presence of single species of Ichthyocotylurus, Strigidae and Bolbophorus, two species of Apharyngostrigea and Posthodiplostomum, one species of Alaria and at least three species of Diplostomids (Diplostomum phoxini, Diplostomum compactum and Diplostomum spathaceum) that were closely related to the sample specimens (Figure 2). The NJ analyses for ITS rDNA (Figure 3) revealed genetic relationship of the sample specimens to two Diplostomum species (Diplostomum mashonense and Diplostomum baeri). The resultant tree presented bootstrap consensus values of $>50 \%$ for almost all branches. The bootstrap (Felsenstein, 1988) consensus tree was inferred from 100 replicates (Figure 3) and 1000 replicates (Figure 2) and taken to represent the relationship of the taxa analyzed. The trees are drawn to scale, with branch lengths in the same units as those of the evolutionary distances used to infer the phylogenetic tree.

\section{Discussion}

The principal findings of this study indicated that multiple species infections of Diplostomum were common in the fish community. These findings were revealed using ITS and 18S ribosomal DNA. Five species of lens-infecting Diplostomum were found to be closely related to the specimens analysed in this study based on the distance matrix method that considered the phenotypic similarities of the species. The use of outgroup taxa (Tylodelphys sp.) that was closely related to Diplostomum and the monophyly of the cryptic species revealed herein, suggested that each species complex originated from a common ancestor. According to this study, ITS sequence data of specimen D32 was closely related to Diplostomum mashonense (Beverley-Burton, 1963). Similarity of specimen D32 to D. mashonense was associated with the resultant tree that presented a bootstrap consensus value of $100 \%$ for the branch (Figure 3). This is in agreement with the observation by [16] who pointed out striking similarity between D. mashonense (Beverley-Burton, 1963) and Tylodelphys spp. 1 and 2, and later discriminated $D$. mashonense (FJ 470402) from Tylodephys spp. using morphometric variability analysis. Similarity between the two Diplostomum species (D. mashonense and D32) suggest a strong association between Diplostomum sp. studied in Tanzania and Diplostomum in Kisumu, Kenya. Thus, similarity in parasite distribution in the different fish host species might be as a consequence of co-evolutionary interactions associated with geographical divergence of the species.

Phylogenetic analysis of ITS rDNA sequence data from adult forms of Diplostomum by [22] lends support to 1 sequence from this study which demonstrated highly similar consensus sequences to D. baeri (JQ 665460) classified as American species (Figure 3). Specimens closely related to D. baeri included D42, D52, D35, D57, D44, D26, and D46 which were equally assessed by ITS rDNA and strongly supported by a high bootstrap value (>99\%). 18S rDNA sequence data was closely related to D. compactum, D. spathaceum and D. phoxini classified as American or European species. Specimen M7 and M10 were closely related to $D$. compactum and $D$. spathaceum, whereas specimens M5-M20 were closely related to $D$. phoxini. Similarity of the specimens to reported Diplostomum sp. was associated with the resultant tree that presented bootstrap consensus values of $>50 \%$ for almost all branches (Figures 2 and 3). The present study therefore provides a preliminary confirmation of diplostomoid species residing in both continents with a possibility of recent divergence or hybridization. Spatial 


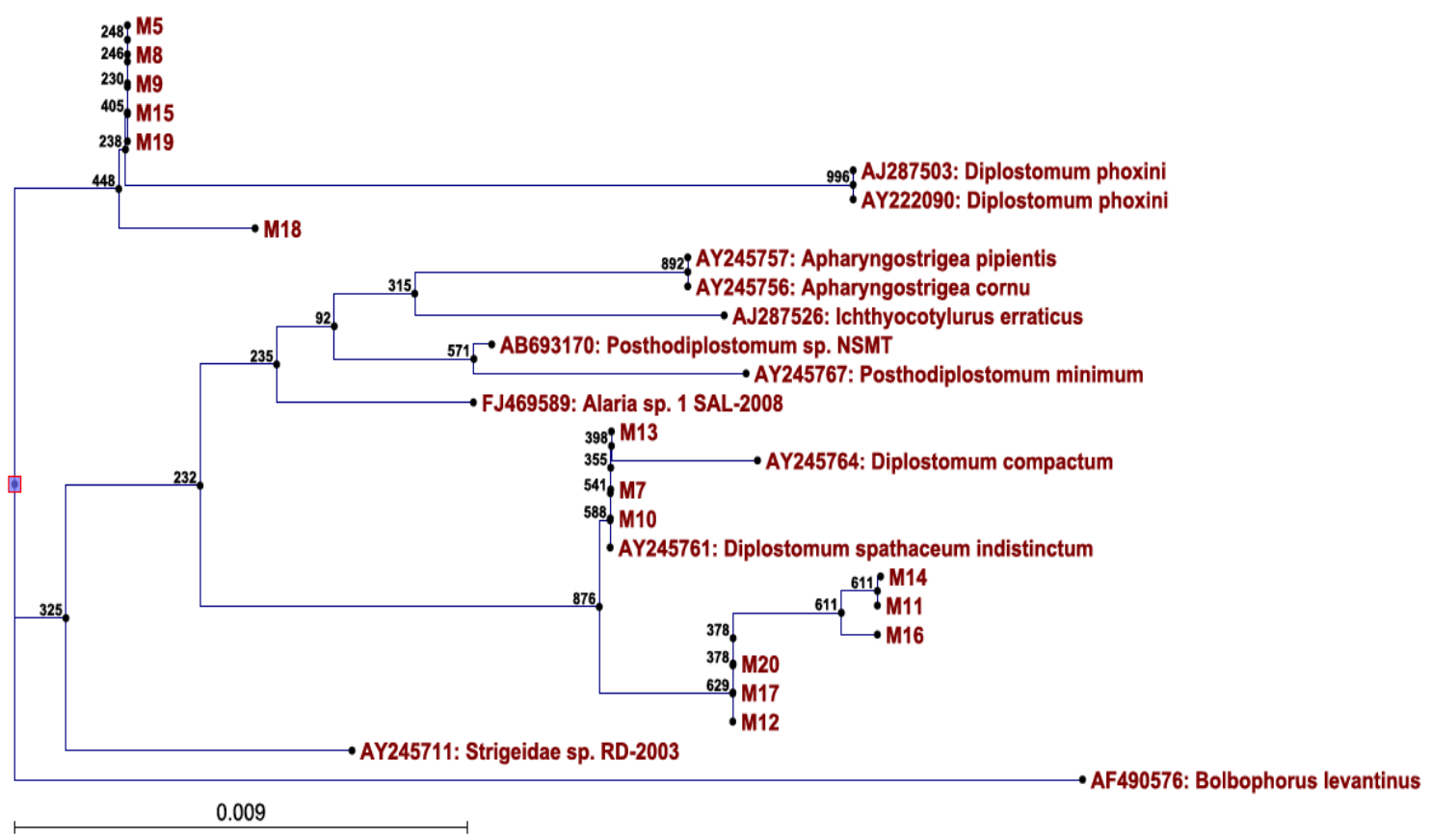

Figure 2. Neighbour joining tree depicting genetic relationship between sample specimens labelled "M" and other reported Diplostomum sp. as inferred from 18S rDNA sequences. Numbers at the nodes represent bootstrap values. Bolbophorus sp. was set as out group.

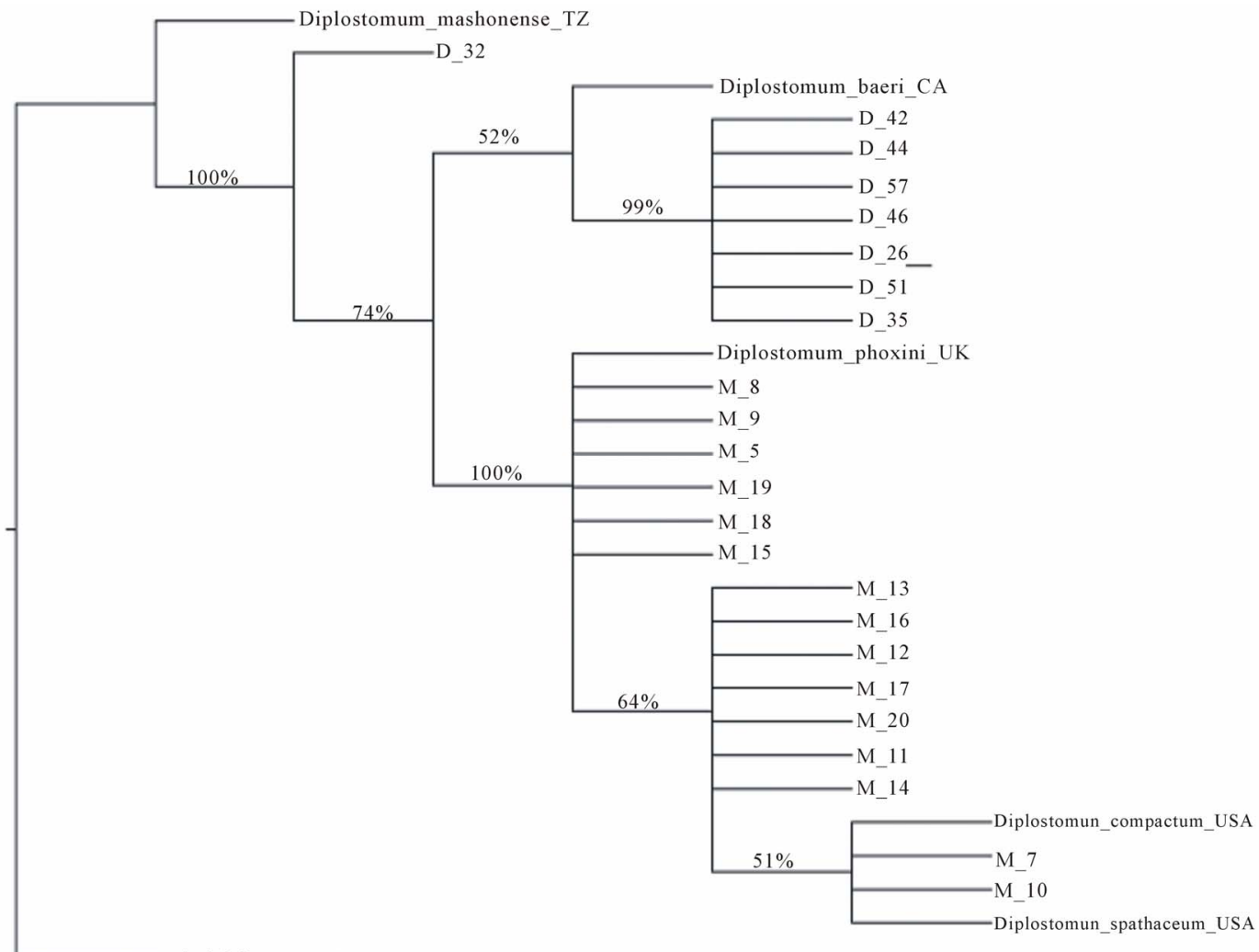

Tylodelphys_sp_TZ

$$
\overline{0.09}
$$

Figure 3. Neighbour-joining tree of sequences constructed in this study in comparison with representatives in the Diplostomum sp. as inferred from ITS rDNA (Specimen labelled D's) and 18S rDNA (Specimen labelled M's) sequences. Numbers at the nodes represent bootstrap values. Tylodelphys spp. was set as an out group. 
distribution of Diplostomum sp. at the three fish locations in Kisumu municipality demonstrated five Diplostomum communities among the fish population. This is an indication of increased gene flow among the parasites making it impossible for only one parasite to adapt to the environment. Although our study was not designed to investigate how definitive hosts influence gene flow in parasites, we gave speculations based on the biological basis of the parasite life cycle. Host mobility has been proposed to be the main determinant of gene flow in parasites since they are commonly dependent on their host for dispersal [36]. According to [37], parasites with complex life cycles such as Diplostomum include multiple host species within their lifecycle and therefore gene flow is expected to be determined by the host with the highest dispersal rate. In this study, it was likely that high mobility in the bird species commonly seen around the farms (the great Egret, Cormorants and Pied-billed Grebe) was sufficient to cause high levels of gene flow among the spatially isolated Diplostomum parasites in the different farms when taking into account that each definitive host can harbour dozens or hundreds of adult parasites.

\section{Conclusion}

Internal transcribed spacer (ITS) and 18S rDNA genes employed in this study successfully provided phylogenetic relationship of Diplostomum genera. Five species of Diplostomum (D. mashonense, D. baeri, D. phoxini, D. compactum, $D$. spathaceum) were genetically related to sample specimens in this study. However, phylogenetic data did not give formal description names to the sample specimens due to lack of sequence links to the adult stages and cercarial stages; this stresses the need for further taxonomic research on this group.

\section{Acknowledgements}

We would like to acknowledge the help from Maseno University Zoology department staff and in particular Phillip Ochieng, James Ojienga and Job Pira for their technical support. We are grateful to Vincent Ochieng' from University of Eldoret, for his assistance in identification of Diplostomum parasites in the field. I would like to thank Ibrahim Ndung'u, Mercy Macharia, Winnie Akoth, Elly munde and Benjamin Opot for their technical support during molecular work. This work was supported by DAAD Kenya.

\section{REFERENCES}

[1] L. H. Chappell, L. J. Hardie and C. J. Secombes, "Diplostomiasis: The Disease and Host Parasite Interactions," In: A. W. Pike and J. W. Lewis, Eds., Parasitic Diseases of Fish, Samara Publishing Limited, Otley, 1994, pp. 5986.

[2] L. H. Chappell, "The Biology of Diplostomatid Eye Flukes of Fishes," Journal of Helminthology, Vol. 69, No. 2, 1995, pp. 97-101. http://dx.doi.org/10.1017/S0022149X00013961

[3] J. N. Stables and L. H. Chappell, "The Epidemiology of Diplostomiasis in Farmed Rainbow Trout from NorthEast Scotland," Parasitology, Vol. 92, No. 3, 1986, pp. 699-710. http://dx.doi.org/10.1017/S0031182000065550

[4] J. S. Field and S. W. Irwin, "The Epidemiology, Treatment and Control of Diplostomiasis on a Fish Farm in Northern Ireland," In: A. W. Pike and J. W. Lewis, Eds., Parasitic Diseases of Fish, Samara Publishing Limited, Otley, 1994, pp. 87-100.

[5] D. J. Marcogliese, P. Dumont, A. D. Gendron, Y. Mailhot, E. Ber-geron and J. D. McLaughlin, "Spatial and Temporal Variation in Abundance of Diplostomum spp. in Walleye (Stizostedion vitreum) and White Suckers (Catostomus commersoni) from the St. Lawrence River," Canadian Journal of Zooolgy, Vol. 79, 2001, pp. 355-369.

[6] C. R. Sangster, A. D. M. Dove and P. R. Bowser, "Diplostomum in Pond-Reared Walleye Stizostedion vitreumImplications of a Management Strategy for Control," Aquaculture, Vol. 236, No. 1-4, 2004, pp. 95-102. http://dx.doi.org/10.1016/j.aquaculture.2004.02.014

[7] K. Buchmann and A. Uldal, "Effects of Eyefluke Infections on Growth of Rainbow Trout (Oncorhynchusmykiss) in Amariculture System," Bulletin of European Association of Fish Pathology, Vol. 14, 1994, pp. 104-107.

[8] T. Paaver, R. Gross and P. Ilves, "Growth Rate, Maturation Level and Flesh Quality of Three Strains of Large Rainbow Trout (Oncorhynchus mykiss) Reared in Estonia," Aquaculture International, Vol. 12, No. 1, 2004, pp. $33-45$.

http://dx.doi.org/10.1023/B:AQUI.0000017185.10472.1d

[9] A. Voutilainen, K. Figueiredo and H. Huuskonen, "Effects of the Eye Fluke Diplostomum spathaceum on the Energetics and Feeding of Arctic Charr Salvelinus Alpines," Journal of Fish Biology, Vol. 73, No. 9, 2008, pp. 2228-2237.

http://dx.doi.org/10.1111/j.1095-8649.2008.02050.x

[10] O. Seppälä, A. Karvonen and E. T. Valtonen, "Manipulation of Fish Host by Eye Flukes in Relation to Cataract Formation and Parasite Infectivity," Animal Behaviour, Vol. 70, No. 4, 2005, pp. 889-894.

http://dx.doi.org/10.1016/j.anbehav.2005.01.020

[11] M. Beverley-Burton, "A New Strigeid, Diplostomum (Tylodelphys) mashonense n. sp., (Trematoda: Diplostomatidae), from the Grey Heron, Ardea cinerea L. in Southern Rhodesia, with an Experimental Demonstration of Part of the Life Cycle," Revue de Zoologie et de Botanique Africaines, Vol. 68, 1963, pp. 291-308.

[12] P. H. King and J. G. Van As, "Description of the Adult and Larval Stages of Tylodelphys xenopi (Trematoda: Diplostomidae) from Southern Africa," Journal of Parasitology, Vol. 83, No. 2, 1997, pp. 287-295. http://dx.doi.org/10.2307/3284458

[13] A. Kostadinova, "A Checklist of Macroparasites of Liza 
Haematocheila (Temminck \& Schlegel 1845) (Mugilidae)," Parasites and Vectors, Vol. 1, 2008, p. 48. http://dx.doi.org/10.1186/1756-3305-1-48

[14] C. J. Mwita and G. Nkwengulila, "Determinants of the Parasite Community of Clariid Fishes from Lake Victoria, Tanzania," Journal of Helminthology, Vol. 82, No. 1, 2008, pp. 7-16.

http://dx.doi.org/10.1017/S0022149X07839745

[15] C. J. Mwita and G. Nkwengulila, "Phylogenetic Relationships of the Metazoan Parasites of the Clariid Fishes of Lake Victoria Inferred from Partial 18S rDNA Sequences," Tanzanian Journal of Sciences, Vol. 37, 2011, pp. 179-185.

[16] F. D. Chibwana and G. Nkwengulila, "Variation in the Morphometrics of Diplostomid Metacercariae (Digenea: Trematoda) Infecting the Catfish, Clarias gariepinus in Tanzania," Journal of Helminthology, Vol. 84, No. 1, 2010, pp. 61-70.

http://dx.doi.org/10.1017/S0022149X09990083

[17] F. Chibwana, I. Blasco-Costa, S. Georgieva, M. K Hosea, G. Nkwengulila, T. Tomaš Scholz and A. Kostadinov, "First Insight into the Barcodes for African Diplostomids (Digenea: Diplostomidae): Brain Parasites in Clarias gariepinus (Siluriformes: Clariidae)," Infection Genetics and Evolution, Vol. 17, 2013, pp. 62-70. http://dx.doi.org/10.1016/j.meegid.2013.03.037

[18] G. K. Matolla, "Parasites of Tilapia (Oreochromis niloticus) in Chepkoilel-Fish Farm of Moi University, Eldoret, Kenya," In: S. S. Drexler and H. Waidbacher, Eds., Proceedings of the 6th Framework Programme on BOMOSA Projects: Integrating BOMOSA Cage Fish Farming System in Reservoirs, Ponds and Temporary Water Bodies in Eastern Africa, Machakos, 2-4 September 2009, p. 28.

[19] E. M. Kembenya, G. K. Matolla, V. Ochieng' and M. Ngaira, "Diplostomum Parasites Affecting Oreochromis niloticus in Chepkoilel Fish Farm and Two Dams in Eldoret-Kenya," International Journal of Scientific \& Engineering Research, Vol. 7, No. 3, 2012, pp. 1-7.

[20] G. N. Madanire-Moyo, W. J. Luus-Powell and P. A. S. Olivier, "Ecology of Metazoan Parasites of Clarias gariepinus (Osteichthyes: Clariidae) from the Nwanedi-Luphephe Dams of the Limpopo River System, South Africa," African Zoology, Vol. 45, No. 2, 2010, pp. 233-243. http://dx.doi.org/10.3377/004.045.0202

[21] J. April, R. L. Mayden, R. H. Hanner and L. Bernatcheza, "Genetic Calibration of Species Diversity among North America's Freshwater Fishes," PNAS, Vol. 108, No. 26, 2011, pp. 10602-10607. http://dx.doi.org/10.1073/pnas.1016437108

[22] D. Gallazzo, E. S. Dayanandan, D. J. Marcogliese and J. D. McLaughlin, "Molecular Systematics of Some North American Species of Diplostomum (Digenea) Based on rDNA-Sequence Data and Comparisons with European Congeners," Canadian Journal of Zoology, Vol. 30, 2002, pp. 2207-2217.

[23] S. Locke, J. D. Mclaughlin, S. Dayanandan and D. J. Marcogliese, "Diversity and Specificity in Diplostomum spp. Metacercariae in Freshwater Fishes Revealed by Cytochrome $c$ Oxidase I and Internal Transcribed Spacer Sequences," International Journal for Parasitology, Vol.
40, No. 3, 2010, pp. 333-343.

http://dx.doi.org/10.1016/j.ijpara.2009.08.012

[24] S. Locke, J. D. Mclaughlin and D. J. Marcogliese, "DNA Barcodes Show Cryptic Diversity and a Potential Physiological Basis for Host Specificity among Diplostomoidea (Platyhelminthes: Digenea) Parasitizing Freshwater Fishes in the St. Lawrence River, Canada," Molecular Ecology, Vol. 19, No. 13, 2010, pp. 2813-2827. http://dx.doi.org/10.1111/j.1365-294X.2010.04713.x

[25] K. Niewiadomska and Z. Laskowski, "Systematic Relationships among Six Species of Diplostomum nordmann, 1832 (Digenea) Based on Morphological and Molecular Data," Acta Parasitologica, Vol. 47, No. 1, 2002, pp. 20-28.

[26] C. Rellstab, K. Louhi, A. Karvonen and J. Jokela, “Analysis of Trematode Parasite Communities in Fish Eye Lenses by Pyrosequencing of Naturally Pooled DNA," Infection, Genetics and Evolution, Vol. 11, No. 6, 2011, pp. 1276-1286. http://dx.doi.org/10.1016/j.meegid.2011.04.018

[27] Republic of Kenya, "Nyando District Development Plan, Nairobi; Kenya," 2002.

[28] National Environmental Management Authority [NEMA], "Strategy for Flood Management in Lake Victoria Basin, Kenya," 2004.

[29] Lake Basin Development Authority, "Feasibility Study on Kano Plain Irrigation Project," Vol. 1, No. 71, 1992.

[30] W. W. Daniel, "Biostatistics: A Foundation for Analysis in the Health Sciences," John Wiley \& Sons, New York, 1999.

[31] S. Yamaguti, "Synopsis of Digenetic Trematodes of Vertebrates," Keigaku Publishing, Tokyo, 1971.

[32] G. E. Truett, R. L. Heeger, A. A. Mynatt, J. A. Truett and M. L. Warman, "Preparation of PCR-Quality Mouse Genomic DNA with Hot Sodium Hydroxide and Tris (HotSHOT)," BioTechniques, Vol. 29, 2000, pp. 52-54.

[33] A. Moszczynska, S. A. Locke, J. D. McLaughlin, D. J. Marcogliese and T. J. Crease, "Development of Primers for the Mitochondrial Cytochrome $c$ Oxidase I Gene in Digenetic Trematodes Illustrates the Challenge of Barcoding Parasitic Helminthes," Molecular Ecology Resources, Vol. 9, No. S1, 2009, pp. 75-82.

[34] K. Luton, D. Walker and D. Blair, "Comparison of Ribosomal Internal Transcribed Spacers from Two Congeneric Species of Flukes (Platyhelminthes: Trematoda: Digenea)," Molecular Biochemistry of Parasitology, Vol. 56, No. 2, 1992, pp. 323-328. http://dx.doi.org/10.1016/0166-6851(92)90181-I

[35] K. Tamura, J. Dudley, M. Nei and S. Kumar, "MEGA 4: Molecular Evolutionary Genetics Analysis (MEGA) Software Version 4.0," Molecular Biology and Evolution, Vol. 24, No. 8, 2007, pp. 1596-1599. http://dx.doi.org/10.1093/molbev/msm092

[36] M. S. Blouin, C. A. Yowell, C. H. Courtney and J. B. Dame, "Host Movement and the Genetic Structure of Populations of Parasitic Nematodes," Genetics, Vol. 141, No. 3, 1995, pp. 1007-1014.

[37] F. Prugnolle, A. Theron, J. P. Pointier, R. Jabbour-Zahab, P. Jarne, P. Durand and T. de Meeus, "Dispersal in a 
Parasitic Worm and Its Two Hosts: Consequence for Local Adaptation," Evolution, Vol. 59, No. 2, 2005, pp.

\section{Abbreviations and Acronyms}

ITS: Internal Transcribed Spacer rDNA: Ribosomal DNA 